\title{
Crystals in brain and meninges in primary hyperoxaluria and oxalosis
}

\author{
M. T. HAQQANI 1 \\ From the Department of Pathology, Stopford Building, University of Manchester
}

SUMMARY A case of primary hyperoxaluria and oxalosis with chronic renal failure, crystalline myocarditis, and disseminated calcium oxalate crystal deposition in various tissues including the brain and meninges is described. Deposition of crystals in brain and meninges is exceptionally rares in primary oxalosis.

Primary hyperoxaluria and oxalosis is considered to be a rare autosomal and recessively inherited disorder (Watts, 1973) in which the rate of oxalate formation is greatly increased (Cochran et al., 1967) and disseminated systemic deposition of calcium oxalate crystals occurs in soft tissues and bones (Scowen et al., 1959). In this report, the occurrence of calcium oxalate crystals is described in brain and meninges in an elderly woman with primary hyperoxaluria and oxalosis, a finding hitherto described only once before in the brain of a 5-week-old baby (Hughes, 1959).

\section{Case report}

A 50-year-old woman presented with anorexia, vomiting, and anuria of three weeks' duration. Hypertension for the previous 10 years had been controlled by hypotensive drugs. On examination the blood pressure was $190 / 95 \mathrm{mmHg}$; anaemia and sacral oedema were present. Laboratory data showed Hb $8 \mathrm{~g} / \mathrm{dl}$, RBC $2.8 \mathrm{million} / \mathrm{mm}^{3}$, WBC $5400 / \mathrm{mm}^{3}$ with a normal differential count, ESR $42 \mathrm{~mm}$ (Westergren), Na $125 \mathrm{mmol} / 1$ (125 mEq/l), K 4.1 $\mathrm{mmol} / \mathrm{l}(4 \cdot 1 \mathrm{mEq} / \mathrm{l}), \mathrm{Cl} 81 \mathrm{mmol} / 1$ ( $81 \mathrm{mEq} / \mathrm{l})$, urea $2.42 \mathrm{mg} / 1(242 \mathrm{mg} / 100 \mathrm{ml})$, and creatinine $2 \mathrm{mg} / \mathrm{l}$ $(20 \mathrm{mg} / 100 \mathrm{ml})$. Peritoneal dialysis was carried out several times without significant clinical improvement. An open renal biopsy revealed tubular necrosis and abundant crystalline debris in the tubules. Later she became hypotensive with bradycardia and ECG changes of right bundle-branch block and died the following day. The clinical diagnosis was that of renal failure due to essential 1Present address: Walton Hospital, Liverpool L9 1AE. Received for publication 24 May 1976 hypertension and ischaemic heart disease. There waš no family history of oxalosis or of calcium oxalate stone formation.

Postmortem examination revealed moderate pleural and pericardial effusions, cardiomegalyo (heart weight $440 \mathrm{~g}$ ), left ventricular hypertrophys (LV weight $270 \mathrm{~g}$; RV $70 \mathrm{~g}$; ratio of left to right ventricular weights $4: 1$ ), slight to moderate athe: roma of the anterior descending branch of the lef $\mathscr{Q}$ coronary artery, and coarsely granular contrac $\overrightarrow{\overrightarrow{0}}$ ted kidneys with a gritty cut surface.

Histologically, all tissues examined revealed calcium oxalate crystals, shown in sections using. polarized light as clusters of yellow birefringen broken plates, or sheaves with a radial rosette-like pattern, or masses of smaller wedge shapes, or isolated deposits. Histochemical confirmation waş. carried out in the tissue sections by the technique described by Johnson (1956). The kidneys showed tubular sludging by the crystals, tubulorrhexis, and crystals in interstitial tissue (Fig. 1). There were changes of essential hypertension in the blood vessels? with crystalline deposition in their walls. In the heart, widespread deposition and a picture of crystalline myocarditis was noted. Deposition of crystals was present in the meninges (Fig. 2) and in walls of congested meningeal vessels. Scanty buk significant deposition was seen in the brain (Fig. 3e with focal mild microglial reaction to their presence

\section{Discussion}

Deposition of calcium oxalate crystals in human? tissues was first described by Lepoutre (1925) cite® by Hughes (1959). A number of accounts have ap? peared in recent years describing their deposition irg 


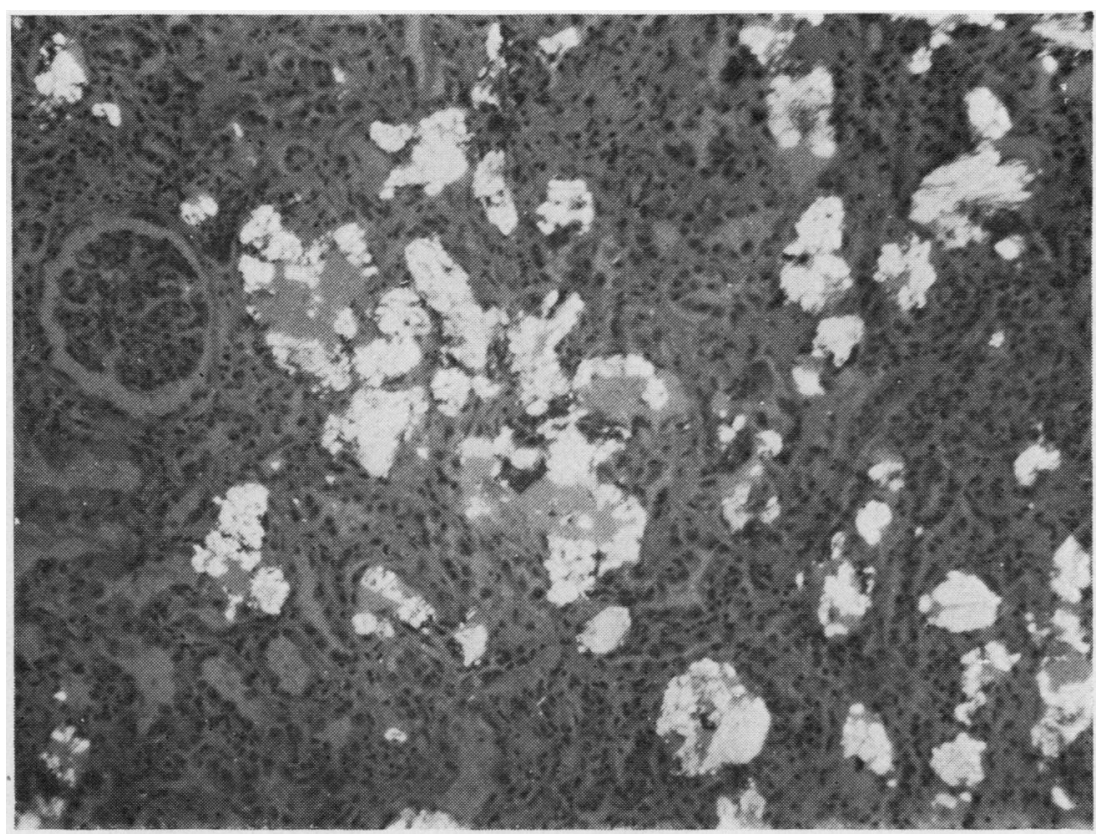

Fig. 1 Widespread crystalline deposition in the kidney $\times 150$.

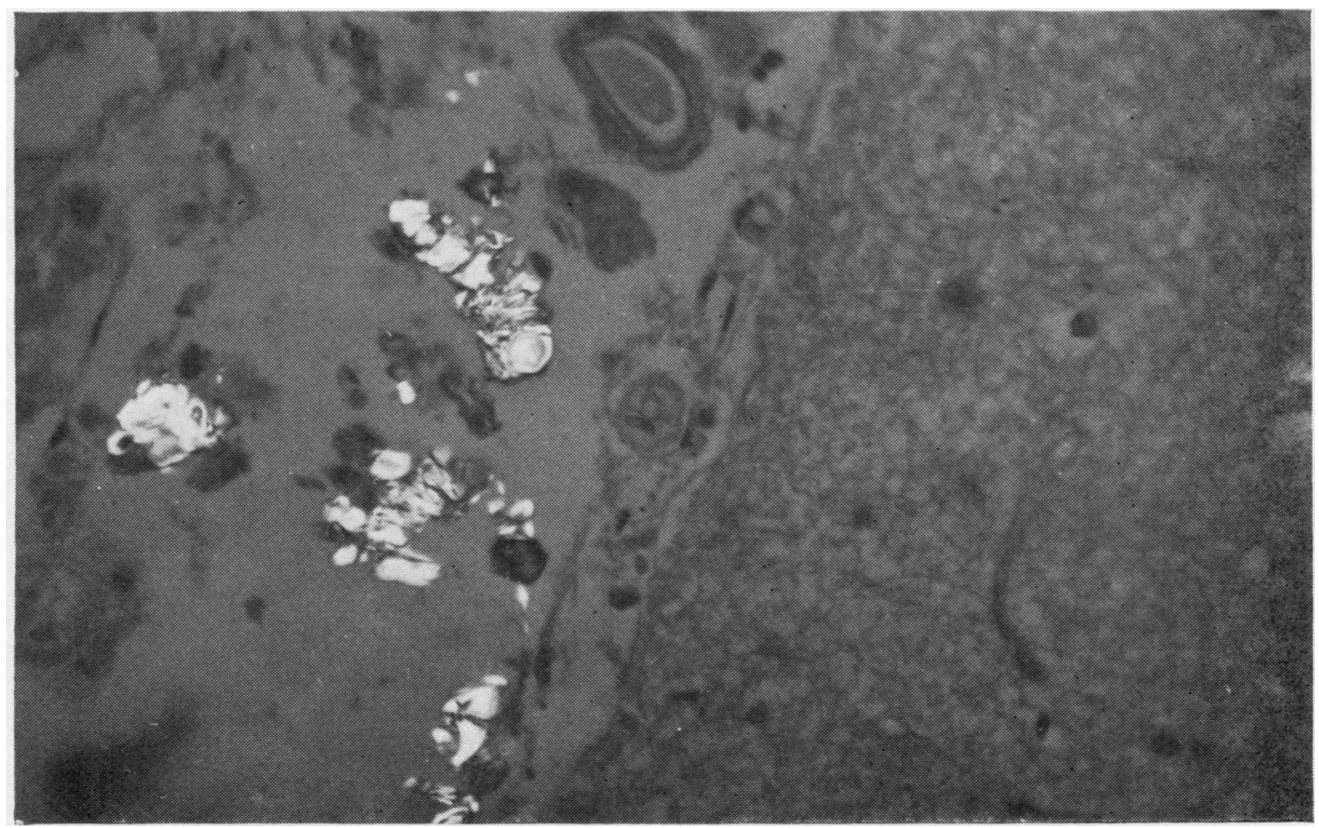

Fig. 2 Crystals in meninges $\times 350$. 


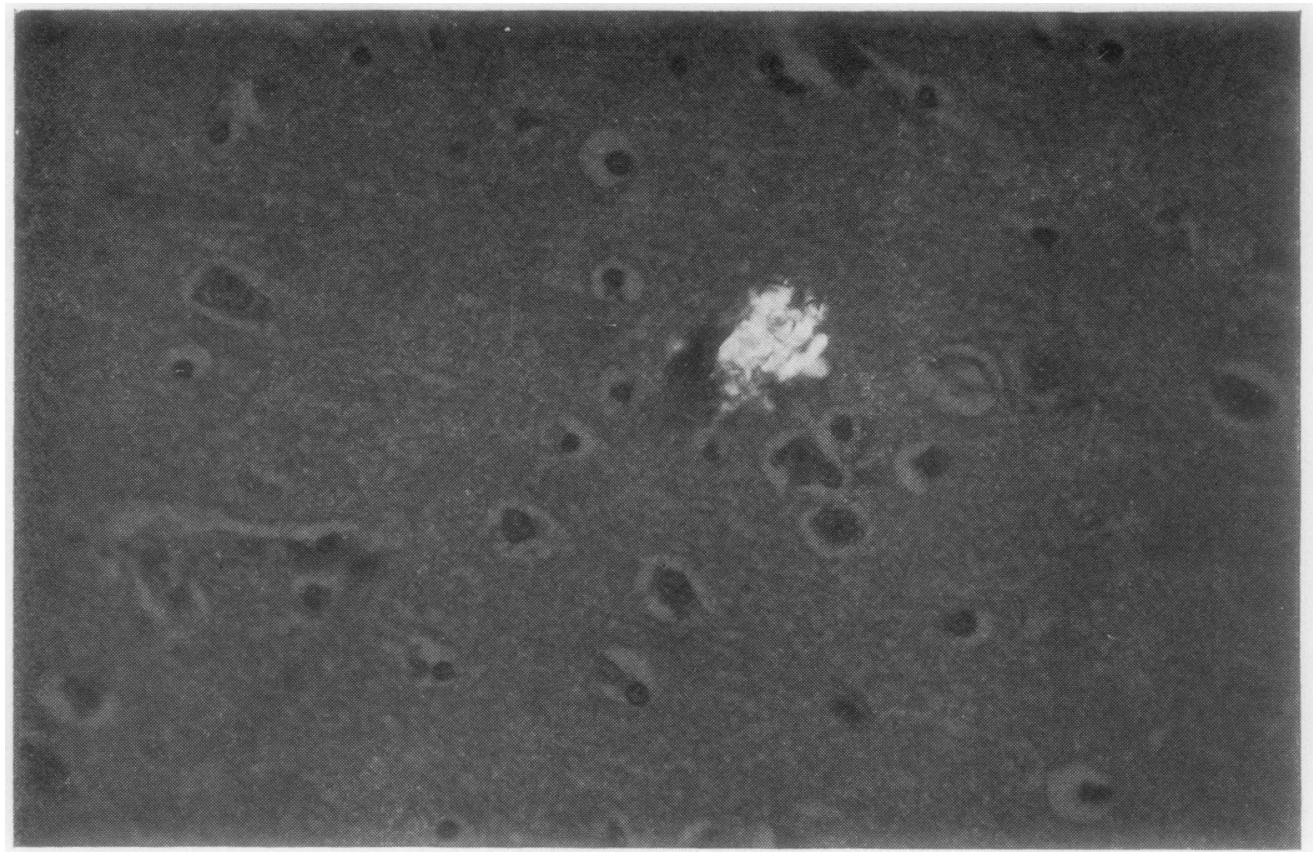

Fig. 3 Crystals in brain $\times 350$.

various tissues, eg, Scowen et al. (1959), Koten et al. (1965), and Hughes (1959) to mention a few. While the crystals are frequently widely distributed, their deposition in the central nervous system appears exceptionally rare. Recently, Moorhead et al. (1975) found calcium oxalate crystals in peripheral nerves which were considered as a cause of progressive peripheral neuropathy in that patient.

In this case, demonstration of the calcium oxalate crystals and their histochemical confirmation led to the postmortem diagnosis of primary hyperoxaluria and oxalosis. The kidneys were the most severely affected organs: the general necropsy findings were basically similar to those in other cases of primary hyperoxaluria and oxalosis described previously by Scowen et al. (1959), Hughes (1959), and Koten et al. (1965), with added changes in the brain and the meninges. In the absence of severe coronary atheroma, the clinical picture of terminal clinical illness, namely, bradycardia with heart block, is consistent with that of primary hyperoxaluria and oxalosis. This may or may not be due to small deposits of calcium oxalate crystals but certain metabolic derangements in the intermediary metabolism of heart muscle mayo well be a factor. Since the nature of the disease was not known at the time of necropsy, a special examina-o tion of the conducting system of the heart was not carried out.

\section{References}

Cochran, M., Hodgkinson, A., Zarambski, P. M., and Anderson, C. K. (1967). Hyperoxaluria in adults. British Journal of Surgery, 55, 121-128.

Hughes, D. T. D. (1959). The clinical and pathological back ground of two cases of oxalosis. Journal of Clinical Path ology, 12, 498-509.

Johnson, F. B. (1956). A method for demonstrating calcium? oxalate in tissue sections. Journal of Histochemistry and Cytochemistry, 4, 404.

Koten, J. W., van Gastel, C., Dorhout Mees, E. J., Holleman L. W. J., and Schuiling, R. D. (1965). Two cases of primary oxalosis. Journal of Clinical Pathology, 18, 223-229"

Moorhead, P. J., Cooper, D. J., and Timperley, W. RO (1975). Progressive peripheral neuropathy in patient with $W_{-}$ primary hyperoxaluria. British Medical Journal, 2, 312-313

Scowen, E. F., Stansfeld, A. G., and Watts, R. W. E. (1959). Oxalosis and primary hyperoxaluria. Journal of Patholog $\mathrm{O}^{\circ}$ and Bacteriology, 77, 195-205.

Watts, R. W. E. (1973). Oxaluria. Journal of the Royal Colleg of Physicians of London, 7, 161-174. 